\title{
Testing and protection of current transformer practical experiences in using the CPC 100
}

\author{
Mohammed Bouchahdane ${ }^{\mathrm{a}}$, Aissa Bouzid ${ }^{\mathrm{b}}$ a* \\ ${ }^{a}$ Signals and systems laboratory, Institute of electrical and electronic engineering,University M'Hamed Bougara Boumerdes, Algeria \\ ${ }^{b}$ Faculty of technology sciences, University of Constantine1,Algeria
}

\begin{abstract}
We notice a recurrent underestimating in all transformer tests despite the huge influence of the accurate transducers on accounting systems. In addition, tests help to significantly reduce the risk of mixing up different instrument transformers or their connections. Tests can also help identify transportation damage inside a transformer. Last but not least, regularly scheduled tests are essential when it comes to detecting effects that can occur within the life cycle of a transformer such as shorted coils, loss of class accuracy due to material changes or changes to the load. Changing the power supply topology and thereby the primary time constant can lead to a situation where the transformer becomes unusable for protection, as it is saturated far earlier than desired due to transient operations. In this paper, we will look at the testing practices for current transformer used by the NATIONAL COMPANY OF ELECTRICITY AND GAS (SONELGAZ Algeria) and show that with the use of the CPC 100 many standard electrical tests for CTs can be performed with one single device saving testing time and labor costs.
\end{abstract}

Keywords: Current transformers, protection, testing, electrical power engineering, diagnostics

\section{Introduction}

Current transformers are very simple - yet are they so complex. A transformer ratio, a magnetization curve and similar can easily be determined. Other parameters, such as unsaturated and saturated inductance or the behavior of a protective core in a short interruption require special measuring processes. Before applying the current transformer in Oum bouaghi substation $60 / 30 \mathrm{kV}$ in the Algerian network, the CT has to be tested for permanence and quality evaluation to make sure that it can work with our protection system properly. These tests include the following:

Insulation resistance, Ratio and polarity, Excitation curve and Winding resistance.

In this paper we will discuss how the CPC 100 of OMICRON is applied for testing the current transformer which offers a broad spectrum of options for highly accurate testing of CT .

Experiences in that matter have been led on that subject on the Oum Bouaghi 60/30 kV substation of the Algerian network, using the $60 \mathrm{kV}$ line of Khenchla [1-3].

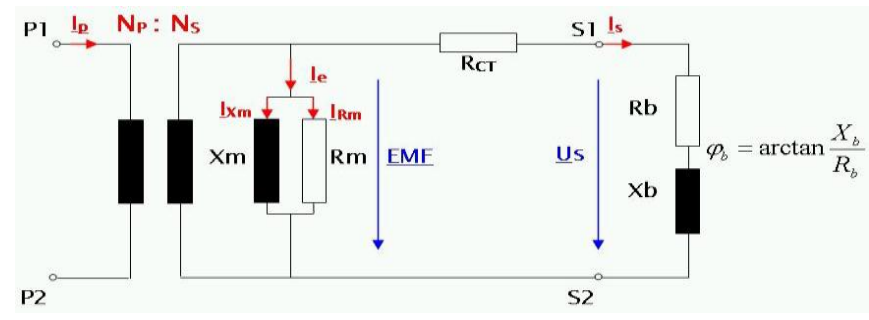

Fig. 1. Equivalent circuit diagram of current transformer.

\footnotetext{
* Manuscript received May 21, 2018; revised February 12, 2019.

Corresponding author. E-mail address: m.bouchahdane@univ-boumerdes.dz.

doi: 10.12720 /sgce.8.2.125-130
} 


\section{Current Transformer Application}

Current transformers are used for relaying and metering purposes in electrical power systems. They connect the high power primary side to the protection and metering equipment on the secondary side. Depending on the application they are used for, current transformers are differently designed [4].

\subsection{Protection current transformers}

As it is used to feed protective relays, the CT must be accurate during normal and fault conditions. Failures in transformation could lead to misoperation of the relay along with unwanted and costly outages. To test CTs according to the requirements of modern protection systems, it is compulsory to consider transient components and auto-reclosure systems.

\subsection{Protection current transformers}

CTs for metering purposes must provide high accuracy up to class 0.1 to guarantee correct billing. It is therefore essential to test and calibrate the metering current transformer, as the entire metering chain is only as accurate as the instrument transformers feeding the meter. In contrast to protection CTs, metering CTs must go into saturation directly above the nominal primary current level to protect the connected metering equipment.

\section{Current Transformer Testing}

Testing current transformers helps to detect:

\subsection{Installation related failures}

Transportation damages, wiring errors and manufacturing defects.

\subsection{In-service related failures}

Degradation of accuracy class, shorted turns, magnetized core, burden failures in secondary circuit and insulation material failures.

\section{Testing and Analyzing the Results}

\subsection{Insulation resistance Testing}

Insulation resistance measurement is a non-destructive measurement method when carried out under normal test conditions. It is done by applying a DC voltage and the aim is to produce a result in $\mathrm{k} \Omega, \mathrm{M} \Omega$ or G $\Omega$. This resistance value expresses the quality of insulation between two conductive elements and gives a good indication as to the risk of leakage currents flowing. The non-destructive nature of this method is useful when tracking the ageing of insulation on a piece of electrical equipment or on an installation as time goes on, so it can also be used effectively as a means of preventative maintenance. This measurement is carried out using an Insulation Tester, otherwise known as a Megohmmeter (Chauvin Arnoux 6549).

Table 2. Current transformer insulation resistance measurement.

\begin{tabular}{|c|c|c|c|c|}
\hline Spotting & $\begin{array}{c}\text { Test voltage } \\
\text { and duration }\end{array}$ & $\begin{array}{c}\text { Phase } \\
\mathbf{0}\end{array}$ & $\begin{array}{c}\text { Phase } \\
\mathbf{4}\end{array}$ & $\begin{array}{c}\text { Phase } \\
\mathbf{8}\end{array}$ \\
\hline Primary / Earth & $5000 \mathrm{Vdc}-1 \mathrm{mn}$ & $231.8 \mathrm{M} \Omega$ & $475 \mathrm{M} \Omega$ & $333.4 \mathrm{M} \Omega$ \\
\hline Primary / Secondary 1 & $1000 \mathrm{Vdc}-1 \mathrm{mn}$ & $19.39 \mathrm{G} \Omega$ & $547 \mathrm{G} \Omega$ & $432 \mathrm{G} \Omega$ \\
\hline Primary / Secondary 2 & $1000 \mathrm{Vdc}-1 \mathrm{mn}$ & $600 \mathrm{G} \Omega$ & $705 \mathrm{G} \Omega$ & $539 \mathrm{G} \Omega$ \\
\hline Secondary 1/ Earth & $500 \mathrm{Vdc}-1 \mathrm{mn}$ & $378 \mathrm{G} \Omega$ & $485 \mathrm{G} \Omega$ & $370 \mathrm{G} \Omega$ \\
\hline Secondary 2 / Earth & $500 \mathrm{Vdc}-1 \mathrm{mn}$ & $461 \mathrm{G} \Omega$ & $626 \mathrm{G} \Omega$ & $500 \mathrm{G} \Omega$ \\
\hline
\end{tabular}




\subsection{Winding resistance}

After entering the test current and pressing the Start button, the test card.

- displays the deviation of the measurement over time during the period of charging the winding.

- automatically performs a discharging of the winding after saving the measurement.

- measures the DC voltage

- measures the resistance

- (optionally) compensates the temperature behavior of copper, where the applied temperature compensation calculates the resistance for working temperature.

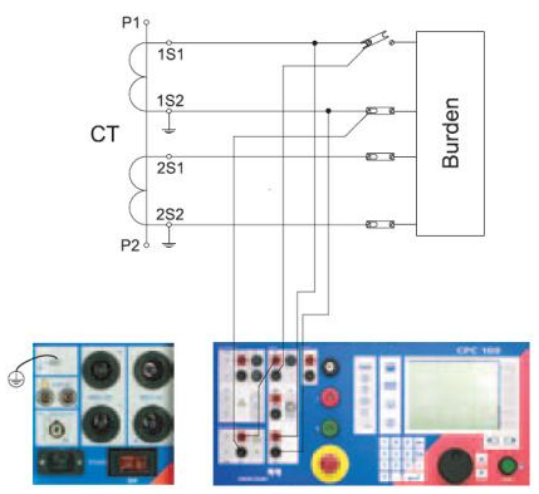

Fig. 2. Connection diagram of CPC100 to CT.

The reference resistance (Rref,temperature-compensated winding resistance) is calculated:

Rref $=($ VDC/IDC $) \times\left(235^{\circ} \mathrm{C}+\right.$ Tref $) /\left(235^{\circ} \mathrm{C}+\right.$ Tmeas $)$

Tmeas: Ambient temperature

Tref: Operating temperature of test object, that is, the power transformer's secondary winding $235^{\circ} \mathrm{C}$ for $\mathrm{Cu}$ and $225^{\circ} \mathrm{C}$ for $\mathrm{Al}$.

Note: Formula according to IEC 60076-1.

Table 3. Results of a current transformer winding resistance measurement.

\begin{tabular}{|c|c|l|c|}
\hline Winding & Idc test & \multicolumn{2}{|l|}{ Phase 0 } \\
\cline { 3 - 4 } & & Temperature measurement & Resistance measurement \\
\hline Measurement Circuit & $2 \mathrm{~A}$ & $10.00^{\circ} \mathrm{C}$ & $\mathbf{3 . 8 4 5 8} \mathbf{\Omega}$ \\
\hline Protection Circuit & $2 \mathrm{~A}$ & $10.00^{\circ} \mathrm{C}$ & $\mathbf{1 . 7 3 0 8 \Omega}$ \\
\hline
\end{tabular}

\subsection{Ratio and polarity}

Supplied from a single phase wall outlet, the CPC 100 can generate up to 800 A AC (2000 A with CP $\mathrm{CB} 2$ current booster) for injecting into the $\mathrm{CT}$ 's primary side and testing its ratio and polarity.

Tests ratio, polarity with direct injection to CT primary current input and measuring of secondary output. After entering I primary, I secondary and test current, and pressing the Start button, the test card measures:

- Secondary current.

- Ratio with error in percent.

- Polarity on the CT terminals.

Iprim: actual current output at the $800 \mathrm{~A} \mathrm{AC}$ output that is injected into the CT's primary side

Isec: measured secondary current and phase angle $\phi$ relative to Iprim

Ratio: ratio Iprim /Isec

The value Isec is calculated as follows: Isec act x (Iprim nom / Iprim act) and deviation of current ratio in $\%$. 
((Kn x Isec - Iprim) / Iprim) x 100\%

$\mathrm{Kn}=$ rated transformation value. Polarity: displays the status of the polarity.

$\mathrm{OK}=$ phase Isec - phase Iprim $=-45^{\circ}<0^{\circ}<+45^{\circ}$

NOT OK $=$ all other cases

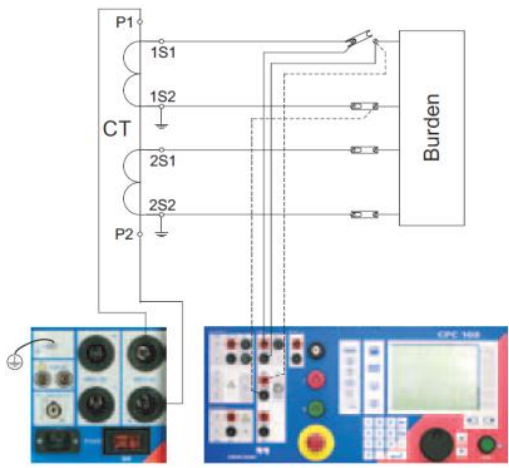

Fig. 3. Connection diagram of CPC100 to CT.

Table 4. Results of a current transformer ratio.

\begin{tabular}{|c|c|c|c|c|c|c|}
\hline Winding & Theoretical ratio & \multicolumn{2}{|l|}{ Phase 0 } \\
\cline { 3 - 7 } & & $\begin{array}{c}\text { I injected } \\
\text { HV side }\end{array}$ & $\begin{array}{c}\text { I injected } \\
\text { LV side }\end{array}$ & Ratio calculated (A) & Error & Polarity \\
\hline Measurement Circuit & $600 / 1$ & $150.0 \mathrm{~A}$ & $249.91 \mathrm{~mA}$ & $\mathbf{6 0 0 A} / \mathbf{0 . 9 9 9 8} \mathrm{A}$ & $\mathbf{- 0 . 0 2} \%$ & OK \\
\hline Protection Circuit & $600 / 1$ & $150.0 \mathrm{~A}$ & $249.61 \mathrm{~mA}$ & $\mathbf{6 0 0 A} / \mathbf{0 . 9 9 8 6} \mathrm{A}$ & $\mathbf{- 0 . 1 4} \%$ & OK \\
\hline
\end{tabular}

\subsection{Excitation curve}

For excitation curve measurement, the CPC 100's output is connected to the secondary terminals of the core. Within an automatic test run, the CPC 100 measures the excitation curve and displays the knee point voltage and knee point current (according to the relevant IEC or IEEE / ANSI standard). The CPC 100 also automatically demagnetizes the CT core after the test. The test is done using a regulated voltage source [5][6][7].

IEC/BS According to IEC 60044-1, the knee point is defined as the point on the curve where a $10 \%$ voltage increment increases the current by $50 \%$.

ANSI $4^{\circ}$ According to IEEE C57.13, the knee point is the point where, with a double logarithmic representation, the tangent line to the curve forms a $45^{\circ}$ angle. Applies to current transformer cores without an air gap.

ANSI $30^{\circ}$ Like ANSI $45^{\circ}$ but forming a $30^{\circ}$ angle. Applies to current transformer cores with an air gap.

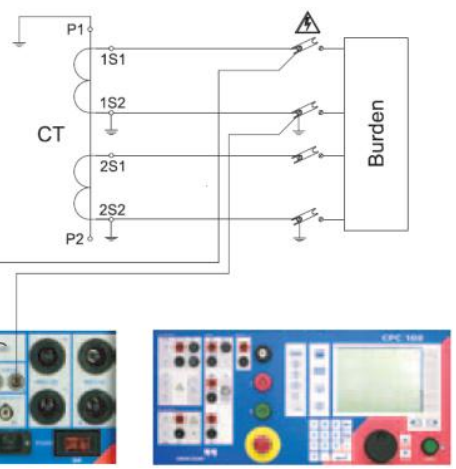

Fig. 4. Connection diagram of $\mathrm{CPC} 100$ to $\mathrm{CT}$ 


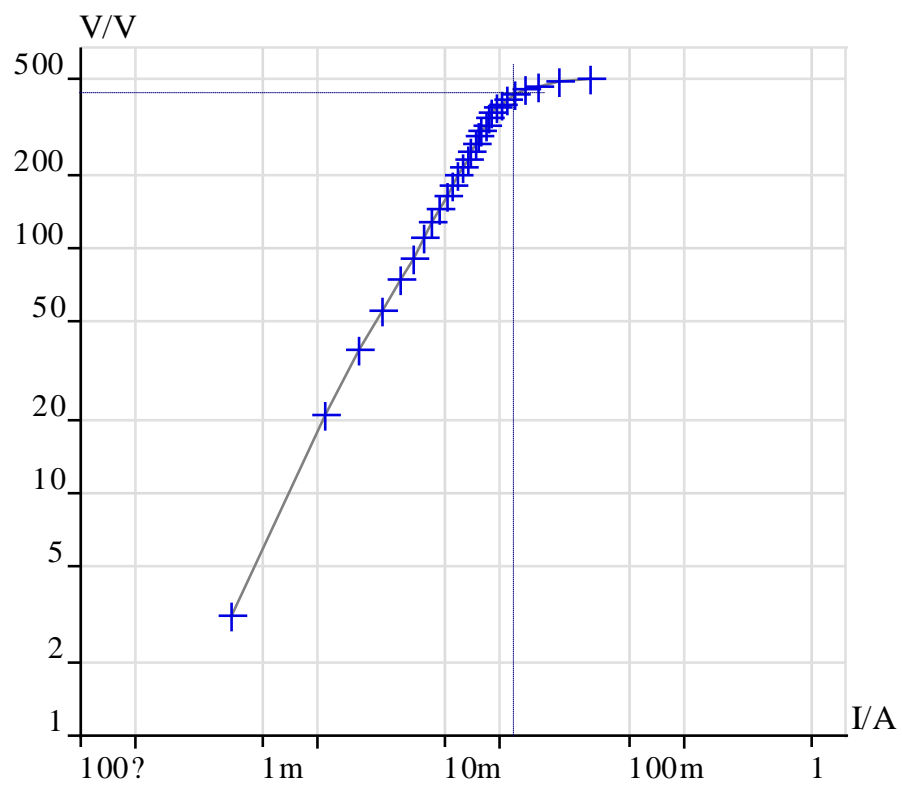

(a)

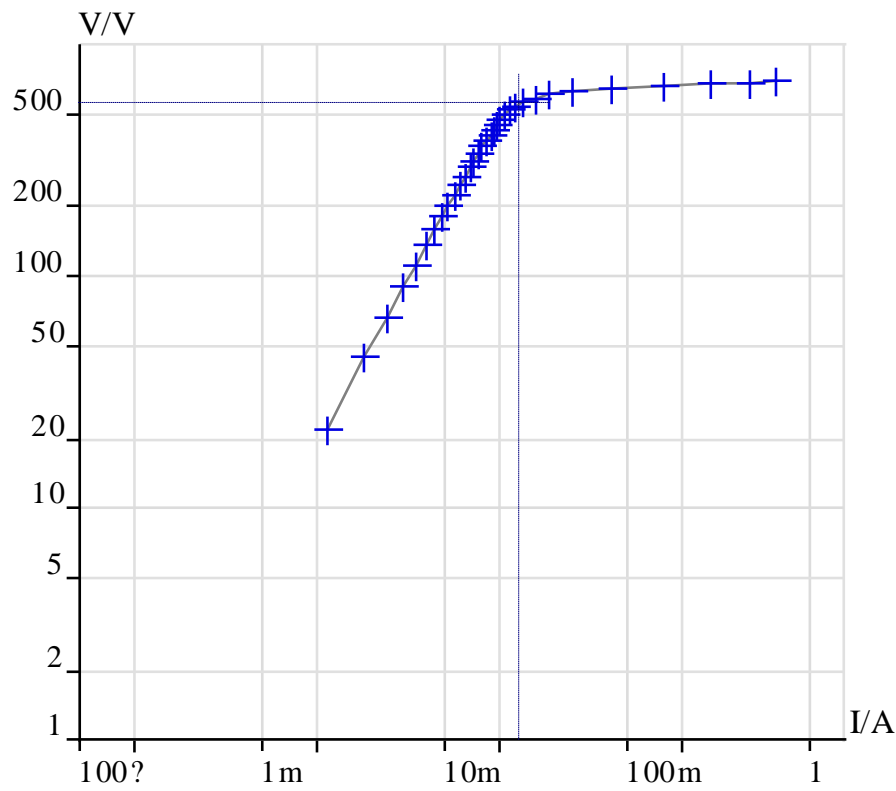

(b)

Fig. 5. Excitation curve of current transformer (phase 0): (a) Measurement circuit and (b) Protection circuit.

Table 5. Results of a current transformer excitation curve measurement (phase 0).

\begin{tabular}{|c|c|l|c|c|c|}
\hline Winding & Frequency & \multicolumn{4}{|l|}{ Phase 0 } \\
\cline { 3 - 6 } & & Imax injected & Vmax injected & V knee point & I knee point \\
\hline Measurement Circuit & $50 \mathrm{~Hz}$ & $1 \mathrm{~A}$ & $600 \mathrm{~V}$ & $\mathbf{4 2 8 . 0 3} \mathrm{V}$ & $\mathbf{2 4 . 0 8 6} \mathbf{~ m A}$ \\
\hline Protection Circuit & $50 \mathrm{~Hz}$ & $1 \mathrm{~A}$ & $900 \mathrm{~V}$ & $\mathbf{5 5 7 . 0 7} \mathbf{V}$ & $\mathbf{2 6 . 1 1 4} \mathbf{~ m A}$ \\
\hline
\end{tabular}




\section{Conclusion}

This paper illustrates with some practical examples in the use of testing CT under actual testing conditions. The measurement results show a very good matching with the values measured by manufacturer. By the time passing and transformers getting older, we need a far more recurrent and regular checks of the operating conditions. In using the omicron CPC 100, the most important current transformer, measurements allow a faster and far more efficient performing. Automatic test procedures enable simple operation and the report is created automatically.

\section{References}

[1] NetSim ,Introductory Examples, Omicron electronics, Klaus 2001.

[2] Keuzunovic M, Formen CW, Phillips F. Experimental evaluation of EMPT- based current transformer models for protective relay study. IEEE Transactions on Power Delivery, 1994; 9(1): 405-413.

[3] Kang YC, Kang SH, Park JK, Johns AT, Aggarwal RK. Development and hardware implementation of a compensating algorithm for the secondary current of current transformers. IEE Proceedings on Electrical Power Application, 1996; 143(1): 41-49.

[4] Omicron Measurement Package Software manual.

[5] IEC60044-6, Instrument Transformers Part6: Requirements for Protective Current Transformers for Transient Performance, internetional Electrotecnical Commission, Geneve, Switzerland, 1992.

[6] IEC60044-1 ,+Amendment 1 (2000) Instrument transformers, Part1: Current transformers, International Electrotecnical Commission, Geneve, Switzerland, 1996.

[7] Krüger M. CTexitation curve testing methods. Energy Source and Distribution, Nundah (Australia) September/October 2001. 